\title{
Pediatric Patient with Incidental Os Odontoideum Safely Treated with Posterior Fixation Using Rod- Hook System and Preoperative Planning Using 3D Printer: A Case Report
}

\author{
Toshinori Sakai ${ }^{1}$ Fumitake Tezuka ${ }^{1}$ Mitsunobu Abe ${ }^{1}$ Kazuta Yamashita ${ }^{1}$ Yoichiro Takata ${ }^{1}$ \\ Kosaku Higashino ${ }^{1}$ Akihiro Nagamachi ${ }^{1}$ Koichi Sairyo ${ }^{1}$ \\ ${ }^{1}$ Department of Orthopedics, Tokushima University Graduate School, \\ Tokushima, Japan \\ Address for correspondence Toshinori Sakai, MD, PhD, Department of \\ Orthopedics, Tokushima University, 3-18-15 Kuramoto, Tokushima \\ 7708503, Japan (e-mail: norinoridowluck@yahoo.co.jp). \\ J Neurol Surg A 2017;78:306-309.
}

\section{Introduction}

Os odontoideum was first described in the late 1880 s. $^{1}$ It is often found incidentally and is asymptomatic, but it can result in neurologic deficits with atlantoaxial dislocation. According to the current management strategies for incidental os odontoideum reported by Klimo et al, patients showing evidence of atlantoaxial instability who are $<20$ years of age should be considered for surgery. ${ }^{2}$

Various techniques for $\mathrm{C} 1-\mathrm{C} 2$ fusion have been described. Posterior sublaminar wiring and $\mathrm{C} 1-\mathrm{C} 2$ transarticular fixation have been frequently used, but they are intricate and may cause neural injury. C1-C2 segmental rod-screw fixation has become the preferred option. ${ }^{3}$ However, various complications can occur with these surgical procedures. Even if the $\mathrm{C} 1-\mathrm{C} 2$ segmental rod-screw fixation is used, sacrifice of the $\mathrm{C} 2$ root is sometimes required to improve visualization. The use of these procedures in children has not gained widespread acceptance because safety and efficacy, of particular importance in pediatrics, have not been demonstrated in pediatric patients.

received

September 4, 2015

accepted

March 24, 2016

published online

May 31, 2016

We present a pediatric case of os odontoideum in which bony union was safely and successfully achieved by posterior fixation using a rod-hook system and perioperative planning.

\section{Case Report}

The patient was a 12-year-old boy who was referred because of C1-C2 instability due to os odontoideum. He fell while playing basketball and bruised the occipital region of his head. Although he had no symptoms, his parents took him to see a local doctor. Radiographs of the cervical spine showed $\mathrm{C} 1-\mathrm{C} 2$ instability due to os odontoideum, but he had neither neck pain nor neurologic findings.

He was referred to our hospital for surgical treatment because of the prominent instability. Plain radiographs showed a bony defect in the dens of $\mathrm{C} 2$ and obvious C1C2 instability (-Fig. 1). After a thorough discussion with his family on the surgical indication, posterior fusion using a rod-hook system for the C1-C2 (3XS system; Kisco DIR, Paris, France) was used. It can be performed more safely

(c) 2017 Georg Thieme Verlag KG Stuttgart · New York
DOI http://dx.doi.org/ 10.1055/s-0036-1584211. ISSN 2193-6315. 

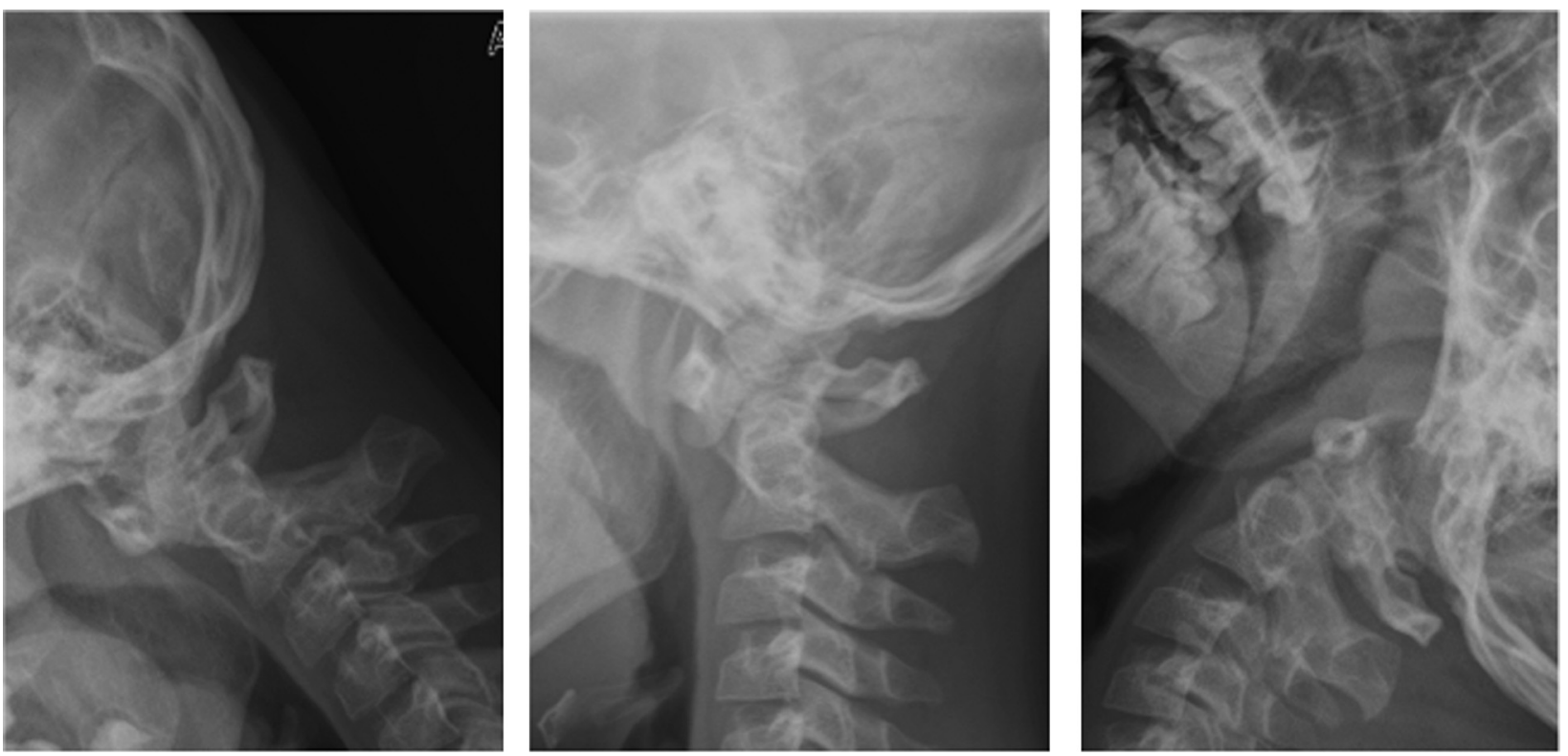

Fig. 1 Plain radiographs showing a bony defect in the dens of $C 2$ and obvious $C 1-C 2$ instability in a pediatric patient.

than the procedure using screws, but stabilization is not as effective.

Preoperatively, we made an actual-size replica of his C1-C2 using a three-dimensional (3D) printer to confirm whether the instrumentation could fit his immature cervical spine ( - Fig. 2A, B). Also, on the day before surgery, we applied the halo vest to acquire a reduced position of $\mathrm{C} 1-$ C2 preoperatively and confirmed that no neurologic deterioration occurred after the reduction $(\mathbf{- F i g . 2 C})$.

The patient underwent posterior fusion with minimal exposure of the muscles; those attached to the $\mathrm{C} 2$ spinous process in particular were preserved as much as possible. The

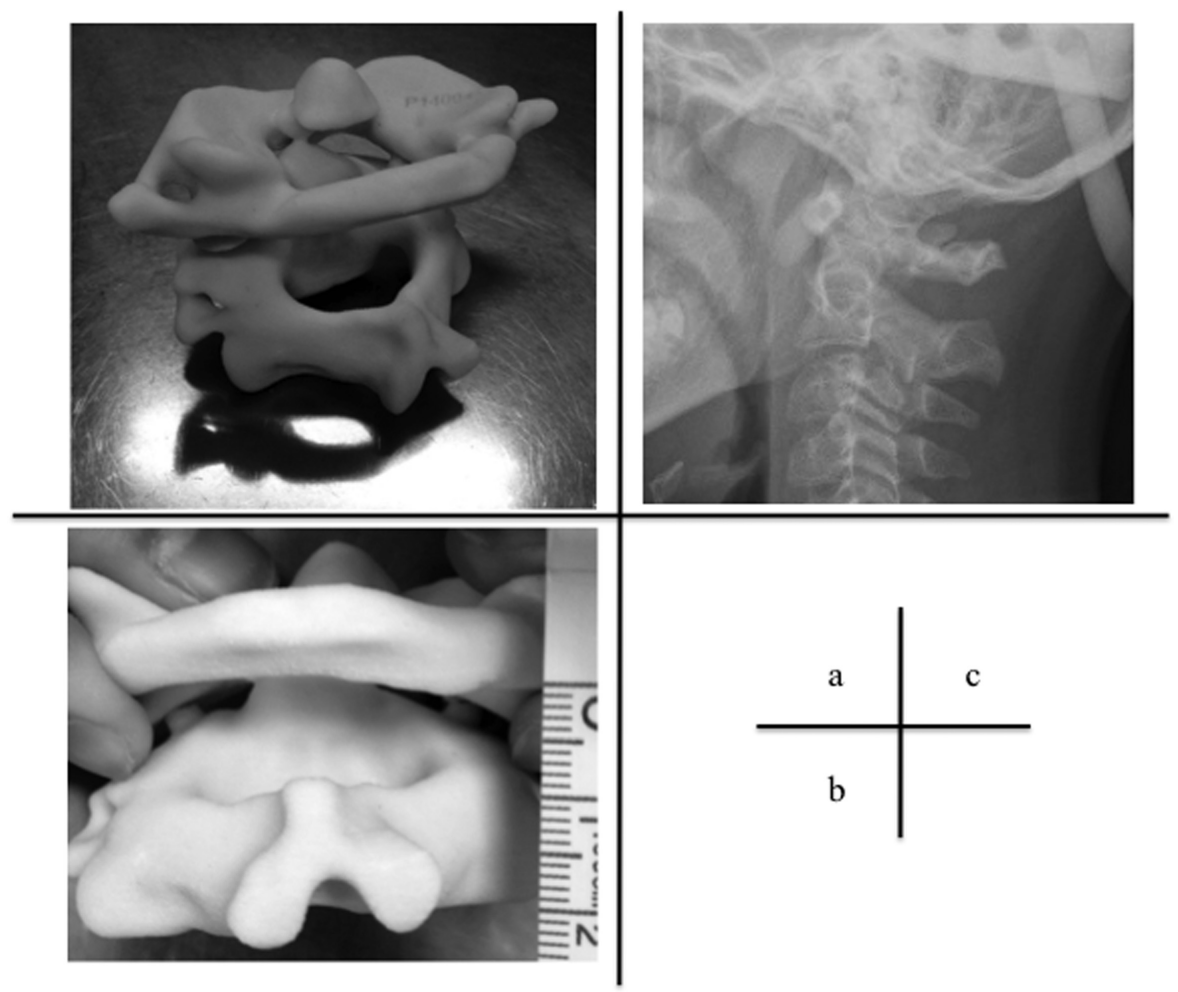

Fig. 2 Preoperative surgical planning. (A) Actual-size replica of C1-C2 created using a three-dimensional printer to confirm whether instrumentation could fit his immature cervical spine. (B) The halo vest was used to acquire a reduced position of C1-C2 preoperatively, and it was confirmed that no neurologic deterioration occurred after the reduction. 
plate and hook system device was placed on the C1 and C2 laminae correctly, and autografted iliac bone was placed on the laminae after decortication. The grafted bone was fixed to the decorticated laminae with Nesplon tape (Alfresa Pharma Corp., Osaka, Japan).

The postoperative course was uneventful, and neurologic deterioration did not occur. External fixation using the halo vest was continued for 3 months after the operation, after which it was removed when bony union was confirmed.

At the 2-year follow-up at age 14, complete bony union of the posterior element was observed. In addition, at the cleft of the divided dens, which had been generally considered as pseudoarthrosis, bone formation was found after bony union of the posterior element of C1-C2 (- Fig. 3 ).

\section{Discussion}

Os odontoideum is a condition in which the $\mathrm{C} 2$ dens lacks bony continuity with the $\mathrm{C} 2$ body. Although its etiology has not been elucidated, two main theories have been proposed: one is related to a congenital abnormality and the other is related to trauma. ${ }^{4}$ In the present case, although the boy visited the first hospital because he had a bruise in the occipital region, he had no symptoms, and plain radiographs showed no new fresh fracture at the $\mathrm{C} 2$ dens. Os odontoideum is most commonly believed to result from remote trauma, but he and his parents had no recollection of an obvious remote traumatic episode. In the present case, bone formation in the gap due to the os odontoideum was obtained after posterior bony fusion was achieved. This result indicates that os odontoideum is not a pseudoarth- rosis and has the potential for bony fusion. Also, it could strongly support the so-called trauma theory.

There have been several reports of asymptomatic cases of os odontoideum. Klimo et al stated in their review article that relatively young patients ( $<20$ years old) with incidental os odontoideum should be strongly considered for surgery. ${ }^{2}$ Screwing including transarticular fixation and segmental rod-screw fixation is considered the most rigid fixation method for C1-C2 instability. However, various complications such as vertebral artery injury have been reported. According to the report by Gluf and Brockmeyer, complications occurred in 7 patients (10.4\%), including 2 vertebral artery injuries, in a cohort of 67 pediatric patients. ${ }^{5}$ In pediatric patients especially, the difficulty of the surgical procedure and associated risks would be higher because the immature spine is anatomically smaller than the mature spine. Also, the screwing system usually requires large exposure, which leads to soft tissue damage, and C2 root sacrifice is sometimes required to improve visualization.

To reduce potential technical errors and critical risks, posterior interlaminar fixation using the 3XS system was applied in this pediatric case. Although critical complications may be avoided using this system, maintenance of stiffness in rotation is relatively weak. Therefore, we used the halo vest until bony union was achieved. Biomechanically, the 3XS system has been proven to be capable of tolerating the rotational forces between $\mathrm{C} 1$ and $\mathrm{C} 2{ }^{6}$

To confirm whether the device fits the pediatric cervical spine correctly, we recreated a full-scale replica of the patient's $\mathrm{C} 1-\mathrm{C} 2$ preoperatively using a three-dimensional
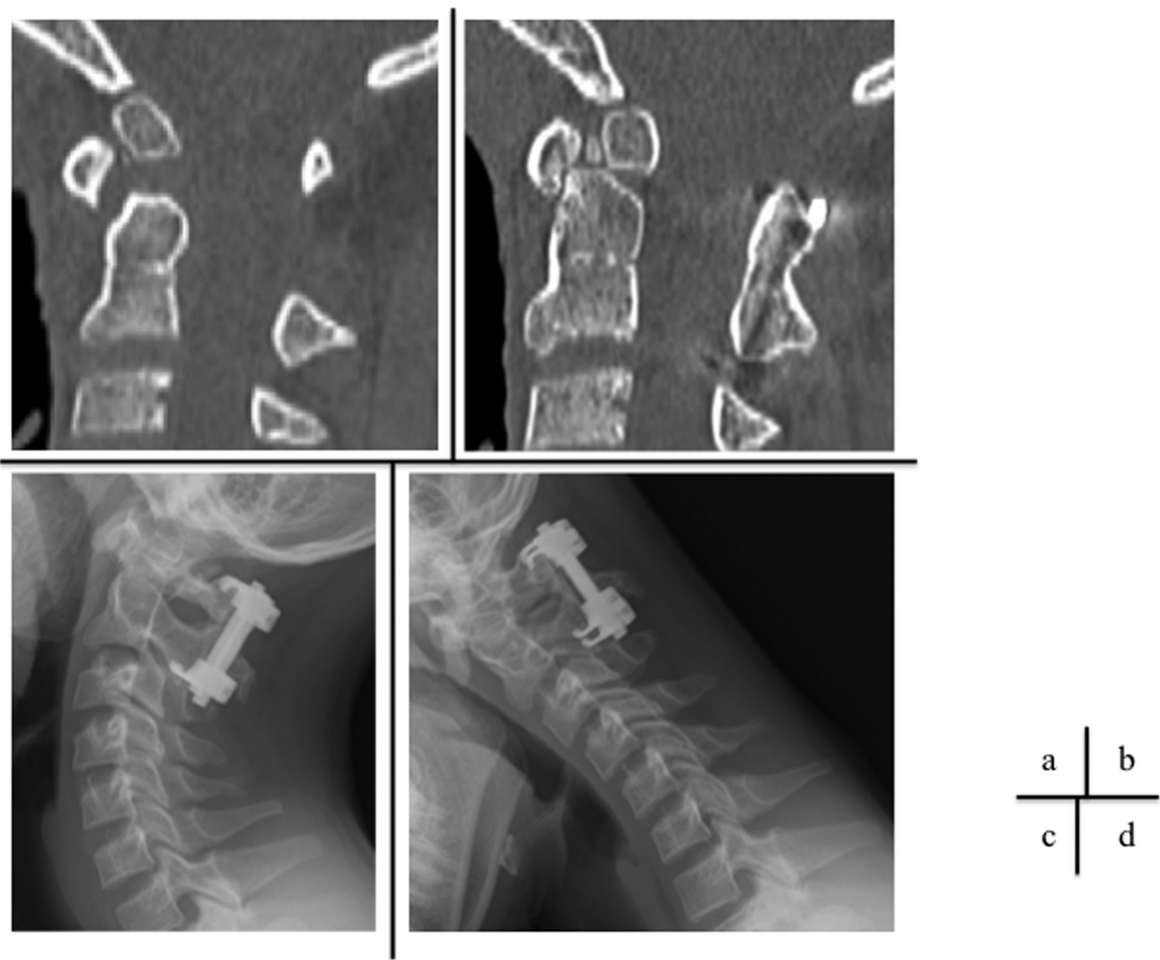

Fig. 3 At the 2-year follow-up, bone formation at the gap of the dens, which has been generally considered as pseudoarthrosis, was found after bony union of the posterior element of $\mathrm{C} 1-\mathrm{C} 2$ occurred. 
(3D) printer. $^{7}$ This virtual planning has recently become popular in several fields, and its adoption will increase the safety of various surgeries, particularly those for pediatric patients.

In conclusion, we believe that preoperative planning using a 3D printer, preoperative reduction of $\mathrm{C} 1-\mathrm{C} 2$ using the halo vest, and posterior interlaminar fixation using a rod-hook system resulted in a safe and good outcome for this patient.

\section{References}

1 Cunningham DJ. Connection of the os odontoideum with the body of the axis vertebra. J Anat Physiol 1886;20(Pt 2):238-243

2 Klimo P Jr, Coon V, Brockmeyer D. Incidental os odontoideum: current management strategies. Neurosurg Focus 2011;31; (6):E10
3 Haque A, Price AV, Sklar FH, Swift DM, Weprin BE, Sacco DJ. Screw fixation of the upper cervical spine in the pediatric population. Clinical article. J Neurosurg Pediatr 2009;3(6):529-533

4 Arvin B, Fournier-Gosselin MP, Fehlings MG. Os odontoideum: etiology and surgical management. Neurosurgery 2010;66(3, Suppl):22-31

5 Gluf WM, Brockmeyer DL. Atlantoaxial transarticular screw fixation: a review of surgical indications, fusion rate, complications, and lessons learned in 67 pediatric patients. J Neurosurg Spine 2005;2(2):164-169

6 Nishizawa S, Yamaguchi M, Matsuzawa Y. Interlaminar fixation using the atlantoaxial posterior fixation system (3XS system) for atlantoaxial instability: surgical results and biomechanical evaluation. Neurol Med Chir (Tokyo) 2004;44(2):61-66; discussion 67

7 Cheung CL, Looi T, Lendvay TS, Drake JM, Farhat WA. Use of 3dimensional printing technology and silicone modeling in surgical simulation: development and face validation in pediatric laparoscopic pyeloplasty. J Surg Educ 2014;71(5):762-767 